\title{
Circadian rhythms of nocturnal hormones in rheumatoid arthritis: translation from bench to bedside
}

\section{Maurizio Cutolo, ${ }^{1}$ Rainer H Straub, ${ }^{2}$ Frank Buttgereit ${ }^{3}$}

Translation from basic research to clinical medicine is complex and needs to be carefully performed. In addition, translational research is needed using human subjects who meet current diagnostic criteria.

Recently, circadian rhythm science has pointed the way to rational intervention on nocturnal hormone production to modulate the immune/inflammatory reactions in patients suffering from rheumatoid arthritis (RA). ${ }^{12}$ These approaches have been introduced into practice with increasing degrees of interest. ${ }^{3}$

We will discuss two recent examples of therapeutically modulating melatonin (MLT) and cortisol as nocturnal hormones implicated in RA clinical circadian rhythms.

\section{CIRCADIAN RHYTHMS AND MORNING STIFFNESS IN RHEUMATOID ARTHRITIS}

It has been known for many decades that disease symptoms in RA follow obvious circadian rhythms, with an increase of activity in the early morning hours, abatement during the day, and a smaller new increase in the early evening (fig 1A). ${ }^{34}$

A number of papers have reported a temporal relationship between elevated levels of pro-inflammatory cytokines and symptoms of RA, such as morning stiffness. ${ }^{4-9}$ Several of these cytokines are highly elevated in patients with active RA in the early hours of the day but after noon they are almost non-existent. Their release pattern and serum concentrations, respectively-possibly triggered by MLT and other hormones or a subordinate neuroendocrine centre in the hypothalamus ${ }^{4}$ follow a strict 24-h daily cycle (fig 1B).

\footnotetext{
${ }^{1}$ Research Laboratories and Clinical Academic Unit of Rheumatology, University of Genova Italy;

${ }^{2}$ Neuroendocrinoimmunology Laboratory, Department of Internal Medicine I, University Hospital, Regensburg, Germany; ${ }^{3}$ Department of Rheumatology and Clinical Immunology, Charité University Medicine, Berlin, Germany
}

Correspondence to: Maurizio Cutolo, Research Laboratories and Clinical Academic Unit of Rheumatology, University of Genova Italy, Viale Benedetto XV, 6, 16132 Genova Italy; mcutolo@unige.it
The closest similarity with the daily pattern of RA symptoms, such as morning stiffness, joint pain and functional disability, seems to exist for interleukin (IL)-6.

Pro-inflammatory hormones start to rise before the onset of RA symptoms and before endogenous cortisol in these patients is activated to counteract the inflammatory cascade of disease symptoms. It should be also noted that rhythmic fluctuations of the nocturnal secretion and the peripheral metabolism of endogenous cortisol, as well as changes in the activation of biologically inactive to active cortisone in the synovial cells, may play a role in the pathophysiology of RA. ${ }^{9} 10$

In patients with RA, inflammation induced changes in synovial fluid composition, oedema of the synovium and periarticular structures, as well as redistribution of interstitial fluid while sleeping, contribute to clinical stiffness of the joints that is most pronounced in the morning. ${ }^{11} 12$ Morning stiffness is also considered to be causally related to the circadian rhythms of pro-inflammatory factors we have discussed above (fig 1).

These processes are closely linked to regulatory interactions between the endocrine, nervous and immune systems, with distinct 24 -h daily rhythms. ${ }^{10}$

The role of IL6 in the regulation of inflammatory and immune responses, particularly in RA, is well established but an increased production of other pro-inflammatory cytokines such as tumour necrosis factor (TNF), IL1, IL8, IL12 and IL17 by primary and secondary immune cells has also been reported. ${ }^{13}$

It has been also discussed that RA is characterised by an inadequate antiinflammatory response that may contribute to morning stiffness. This lack of anti-inflammatory response is not yet totally understood.

\section{MELATONIN IN INFLAMMATION AND RHEUMATOID ARTHRITIS}

A positive genetic relationship between MLT and RA has been recently suggested. ${ }^{14}$
In 2002, our first study evaluated MLT levels in patients with RA with a focus upon analyses of circadian variations. ${ }^{15}$ MLT serum levels at $8 \mathrm{pm}$ and 8 am were found to be significantly higher in patients with RA than in healthy controls $(p<0.05)$. The differences were more evident in patients who were older than 60 years. In patients with RA and in healthy subjects, MLT levels increased progressively from $8 \mathrm{pm}$ to the early morning hours; however, they reached peak levels at midnight in patients with RA, which was at least $2 \mathrm{~h}$ earlier than in controls. Subsequently, MLT concentrations in RA reached a plateau that lasted for $2-3 \mathrm{~h}$; this was not observed in controls. The study confirmed that the nocturnal rhythm of MLT occurs also in patients with RA, but with an earlier peak and a broader plateau in the early morning.

In human peripheral blood mononuclear cells, at physiological concentrations MLT has been reported to stimulate the production of interferon- $\gamma$ (IFN $\gamma$ ), IL1, IL2, IL6 and IL12, but not IL4. ${ }^{16}{ }^{17}$ In addition, MLT was found to enhance production of inflammatory cytokines from cultured human monocytes/macrophages, including IL12 and turning the MLT/IL2 connection towards the enhancement of $\mathrm{T}$ cell immunity. ${ }^{18}$ MLT was found to be detectable at high concentration in synovial fluids from patients who had RA, and binding sites for MLT were present in synovial macrophages. ${ }^{19}$

Interestingly, IFN $\gamma$, IL1, IL6, IL2, IL12 and tumour necrosis factor $\alpha$ (TNF $\alpha$ ) production, (Th1 cytokines/promoting cytokines) reach their peak during the night and early morning, shortly after MLT serum levels are highest and plasma cortisol is lowest. Therefore, we believe that MLT upregulates cytokine production and immune function. ${ }^{20}$ Accordingly, among the signs of joint inflammation in patients with RA, the intensity of pain varies as a function of the hours of the day; pain is greater after waking in the morning than in the afternoon or evening (fig 1A). ${ }^{4}$

Circadian changes are also observed in joint swelling and finger size in the early morning in patients affected by RA. Studies on experimental granulomatous lesions confirmed that the rhythm of the inflammatory reaction is due to the rhythmic MLT release by the pineal gland. ${ }^{21}$ Therefore, MLT may activate the inflammatory response during the night, at least in RA, which is mainly considered to be a Th1 cytokine driven immune disease. 

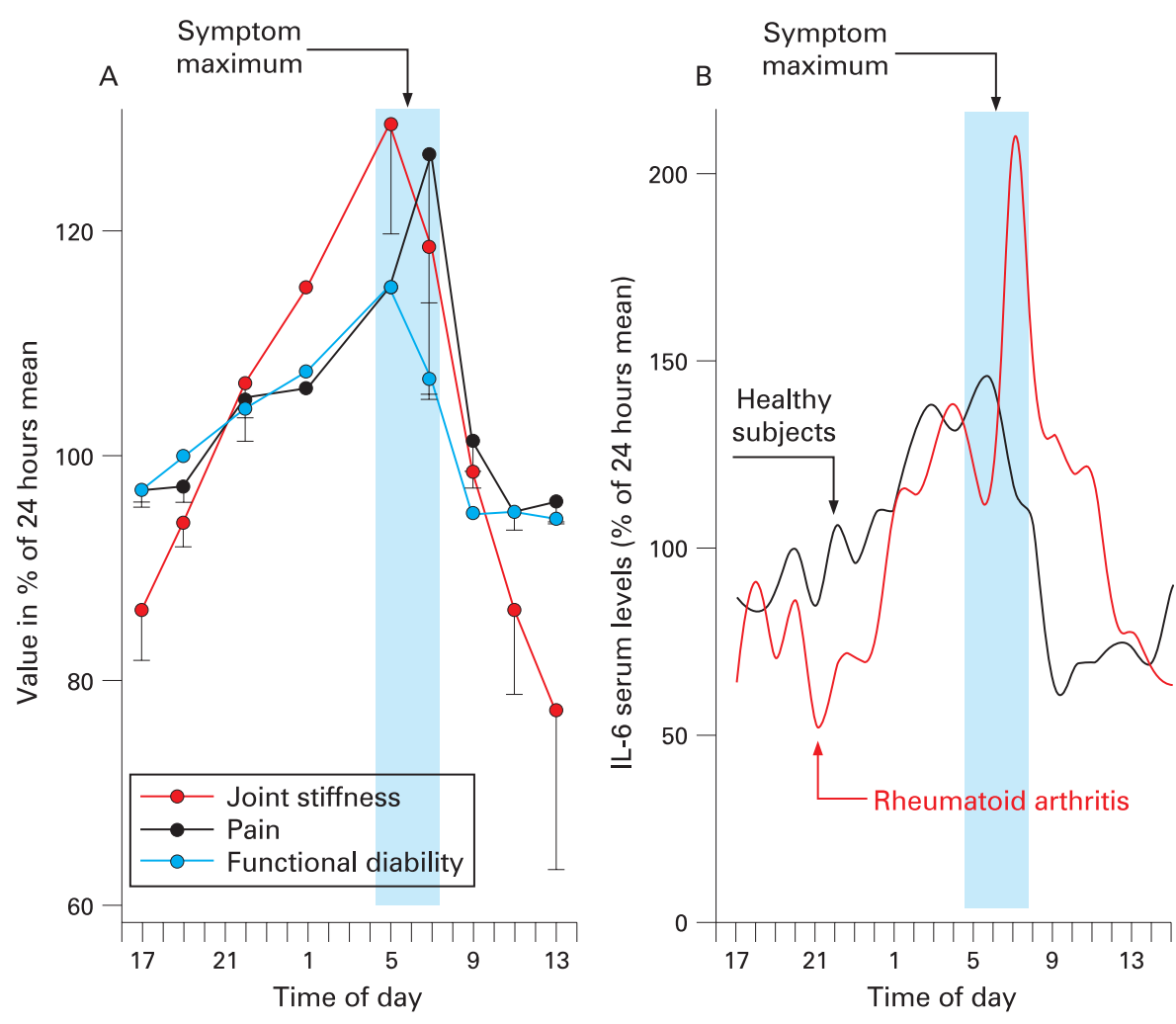

Figure 1 Circadian rhythm of symptoms and interleukin (IL)-6. A. The graph depicts the circadian rhythm of joint stiffness, pain and functional disability. B. The circadian rhythm of IL6 secretion in healthy subjects (black line) and patients with rheumatoid arthritis (red line). The data are given as percentages of the 24-h mean value of the respective variable.

However, MLT is also one of the most efficacious antioxidant compounds in mammals being at least as active as vitamin $\mathrm{E}$ in its ability to scavenge hydrogen peroxide and the highly destructive hydroxyl and peroxynitrite anions. ${ }^{22}$

\section{MELATONIN FROM BENCH TO BEDSIDE IN RA}

An earlier study in patients with RA suggested that blood MLT levels were found decreased consistent with the possibility that the loss of its antioxidant activity could contribute to the disease. ${ }^{23}$ As until recently there was still a need to obtain clinically-based evidence about the possible role of MLT as disease-promoting or -protecting hormone in RA, a doubleblind placebo controlled study investigating the effects of MLT administration in patients with RA was initiated. ${ }^{24}$

The results obtained were somewhat disappointing and surprising, as the authors stated in the discussion. ${ }^{25}$ MLT decreased the levels of lipid peroxidation, but increased erythrocyte sedimentation rate and neopterin levels compared with patients treated with placebo, consistent with an antioxidant effect but also suggesting some pro-inflammatory activity.
In addition, no improvement of RA disease was observed, and in some cases the disease appeared to be worse.

Recently, serum TNF $\alpha$ was found to be higher in Northern European patients with RA than in their controls and was found to be significantly correlated with the increased serum MLT concentrations, at least during the winter. ${ }^{26}$ Therefore, increased serum concentrations and circadian rhythm of MLT and a "relative adrenal insufficiency" in chronic RA (low cortisol), allows Th1 type cytokines to be produced in higher amounts during the late night under the enhancing effect of pineal hormone. ${ }^{3}$

In conclusion, the translation from basic research to clinical medicine clearly showed that MLT treatment does not improve RA. ${ }^{27}$

\section{IMPROVING MORNING STIFFNESS: SUCCESSFUL TARGETING OF PATHOPHYSIOLOGICAL RHYTHMS}

Cortisol secretion and glucocorticoid receptor density has been reported to be altered in patients with RA. ${ }^{28}$ Furthermore, circadian changes of peripheral metabolism of endogenous glucocorticoids may also contribute to the early morning manifestation of the disease symptoms in RA. ${ }^{4}$ Based on these considerations, it has been suggested that the usual administration of glucocorticoids between 6 and 8 am is not optimal. ${ }^{4}$ This could simply be too late since the night-time pathophysiological processes have already lead to inflammation, pain and subjective symptoms..$^{3-5729-31}$ Consequently, it has been hypothesised that it could be easier to prevent the circadian increase of pro-inflammatory cytokine levels and, therefore, the consequently observed clinical signs and symptoms of the disease than to treat these signs and symptoms once they are established in the morning.

In an early study, patients with active RA were woken at 2 am in order to take their usual glucocorticoid drug. It turned out that this procedure indeed had better effects on severe morning RA symptoms than the same dose of drug did if administered at $7.30 \mathrm{am}^{7}$ However, regular waking of the patients is impractical for the therapeutic regimen and will on its own influence the hypothalamicpituitary-adrenal (HPA) axis. ${ }^{32}$

These observations led to the development of a new modified-release prednisone tablet formulation. ${ }^{4}$ This oral prednisone tablet is taken at bedtime and releases the active drug at about 2 am. This results - but with a delay of about $4 \mathrm{~h}$-in a pharmacokinetic profile and a total drug exposure almost identical to that of conventional prednisone.

The efficacy and safety of this novel medication has been recently investigated in a study of 288 patients with active RA, half of which were randomised to receive a modified-release prednisone tablet, and the other half a standard prednisone tablet. Morning stiffness of the joints was measured in both groups and the target variable for the statistical analysis was the mean relative change of duration of morning stiffness at 12 weeks. This mean relative change was much higher for the modified tablet group $(-22.7 \%)$ vs the standard tablet group $(-0.4 \%)(p=0.045)$.

In terms of the actual time the duration of the morning stiffness was reduced for both treatments vs baseline, but the reduction was also much higher in the modified group (44.0 min) compared to baseline. The absolute difference in minutes between the treatments at 12 weeks was $29.2 \mathrm{~min}(p=0.072)$ in favour of the modified tablet. The safety profile was the same for both treatments. ${ }^{4}$

It was concluded that the new modified-release formulation is clinically 
and statistically better than the conventional immediate-release preparation with regard to morning stiffness of the joints. Furthermore, the effects of the new tablet taken at night were achieved in addition to the established clinical control of the disease resulting from treatment with conventional immediaterelease prednisone.

This result is considered to be relevant for daily clinical practice. ${ }^{32}$ The reason is that severe morning stiffness limits function, especially grip strength. Morning stiffness is part of the American College of Rheumatology (ACR) classification and remission criteria and also part of the early referral recommendation for newly diagnosed rheumatoid arthritis. ${ }^{33-35}$ However, it is currently-in contrast to eg, pain, functional limitations, quality of life and ability to work-relatively neglected in clinical studies.

From another recently published study it has been concluded that, in patients with early RA, the degree of morning stiffness appears to reflect functional disability and pain better than traditional markers of inflammation such as joint counts and erythrocyte sedimentation rate (ESR). ${ }^{36}$ It has also been shown that the variables swollen joint count and morning stiffness are more predictive for a change in treatment than, for example, C-reactive protein or tender joint count. ${ }^{37}$ We conclude from these data that morning stiffness has a considerable impact on the patient's quality of life and that it is worth developing treatment strategies that more intensively aim at reducing its duration. Nevertheless, further studies are warranted to investigate the long-term effects of new treatment regimens such as those relating to timing of basic inflammatory processes and the entire range of RA symptoms, including pain. ${ }^{38} 39$

\section{CONCLUSIONS}

Successful or unsuccessful application of pathophysiological concepts in RA resulted in the abandoning of therapeutic strategies or successful translation from bench to bedside. By considering a supposed beneficial role of MLT in RA therapy, the translation from basic research to clinical medicine clearly showed that MLT treatment worsens the disease.

By contrast, the night-time administration of prednisone based on circadian rhythms established a clinical improvement of the disease superior to morning administration. Further steps along this route will include studies to answer the question whether the new time-related approach demonstrates that a given glucocorticoid dose is more effective and/ or less deleterious. In addition, it should also be shown whether this strategy has benefits in other rheumatic and nonrheumatic diseases that are characterised by severe inflammatory early morning symptoms. $^{432}$

Acknowledgements: MC would like to thank Georges Maestroni (Lugano, Switzerland) for his continuous support and expert cooperation on melatonin research.

Competing interests: None declared.

Accepted 8 March 2008

Ann Rheum Dis 2008;67:905-908

doi:10.1136/ard.2008.088955

\section{REFERENCES}

1. Petrovsky N, McNair P, Harrison LC. Diurnal rhythms of pro-inflammatory cytokines: regulation by plasma cortisol and therapeutic implications. Cytokine 1998; 10:307-12

2. Cutolo M, Otsa K, Aakre 0, Sulli A. Nocturnal hormones and clinical rhythms in rheumatoid arthritis. Ann NY Acad Sci 2005;1051:372-82.

3. Straub RH, Cutolo M. Circadian rhythms in rheumatoid arthritis: implications for pathophysiology and therapeutic management. Arthritis Rheum 2007;56:399-408.

4. Buttgereit $\mathbf{F}$, Doering G, Schaeffler, A, Witte $S$, Sierakowski S, Gromnica-lhle E, et al. Efficacy of modified-release versus standard prednisone to reduce morning stiffness of the joints in rheumatoid arthritis (CAPRA-1): a double blind, randomised controlled trial. Lancet 2008;371:205-14.

5. Cutolo M, Masi AT. Circadian rhythms and arthritis. Rheum Dis Clin North Am 2005;31:115-29.

6. Cutolo M, Seriolo B, Craviotto C, Pizzorni C, Sulli A. Circadian rhythms in RA. Ann Rheum Dis 2003;62:593-6.

7. Arvidson NG, Gudbjörnsson B, Elfman L, Rydén AC Tötterman $\mathrm{TH}$, Hällgren R. Circadian rhythm of serum interleukin-6 in rheumatoid arthritis. Ann Rheum Dis 1994:53:521-4.

8. Cutolo M, Villaggio B, Otsa K, Aakre 0, Sulli A, Seriolo B. Altered circadian rhythms in rheumatoid arthritis patients play a role in the disease's symptoms. Autoimmun Rev 2005;4:497-502.

9. Schmidt M, Weidler C, Naumann H, Anders S, Schölmerich J, Straub RH. Reduced capacity of the reactivation of glucocorticoids in rheumatoid arthrits synovial cells: possible role of the sympathetic nervous system? Arthritis Rheum 2005:52:1711-20.

10. Cutolo M, Straub RH, Bijlsma JWJ. Neuroendocrineimmune interactions in synovitis. Nat Clin Pract Rheumatol 2007;3:627-34.

11. Kurana R, Berney SM. Clinical aspects of rheumatoid arthritis. Pathophysiology 2005;12:153-65.

12. Choy EHS, Panayi GS. Cytokine pathways and joint inflammation in rheumatoid arthritis. New Eng J Med 2001:344:907-16.

13. Tak PP. Examination of the synovium and the synovial fluid. In: Firestein GS, Panayi G, Wollheim F eds. Rheumatoid arthritis. Oxford, UK: Oxford University Press, 2006: 229-41.

14. Ha E, Choe BK, Jung KH, Yoon SH, Park HJ, Park HK, et al. Positive relationship between melatonin receptor type 1B polymorphism and rheumatoid factor in rheumatoid arthritis patients in the Korean population. $J$ Pineal Res 2005;39:201-5.

15. Sulli A, Maestroni GJM, Villaggio B, Hertens E, Craviotto C, Pizzorni C, et al. Melatonin levels in rheumatoid arthritis. Ann NY Acad Sci 2002;966:276-83.
16. Garcia-Maurino S, Gonzalez-Haba MG, Calvo JR, Rafii-El-Idrissi M, Sanchez-Margalet V, Goberna R, et al. Melatonin enhances IL-2, IL-6, and IFN-C production by human circulating CD4+ cells. J Immunol 1997;159:574-81.

17. Garcia-Maurino S, Pozo D, Carillo-Vico A, Calvo JR, Guerero JM. Melatonin activates Th1 lymphocytes by increasing IL-12 production. Life Sci 1999;65:2143-50.

18. Cutolo M, Villaggio B, Candido F, Valenti S, Giusti M Felli $L$, et al. Melatonin influences interleukin-12 and nitric oxide production by primary cultures of rheumatoid synovial macrophages and THP-1 cells. Ann NY Acad Sci 1999:876:246-54.

19. Maestroni GJ, Sulli A, Pizzorni C, Villaggio B, Cutolo M. Melatonin in rheumatoid arthritis: synovial macrophages show melatonin receptors. Ann NY Acad Sci 2002;966:271-5.

20. Cutolo M, Maestroni GJ. The melatonin-cytokine connection in rheumatoid arthritis. Ann Rheum Dis 2005:64:1109-11.

21. Lopes C, deLyra JL, Markus RP, Mariano M. Circadian rhythm in experimental granulomatous inflammation is modulated by melatonin. J Pineal Res 1997;23:72-8.

22. Tan DX, Manchester LC, Reiter RJ, Plummer RF, Limson J, Weintraub ST, Oi WB. Melatonin directly scavenges hydrogen peroxide: a potentially new metabolic pathway of melatonin transformation. Free Rad Biol Med 2000:29:1177-85.

23. West SK, Oosthuizen JM. Melatonin levels are decreased in rheumatoid arthritis. J Basic Clin Physiol Pharmacol 1992;3:33-40.

24. Maestroni GJ, Cardinali DP, Esquifino Al, PandiPerumal SR. Does melatonin play a disease-promoting role in rheumatoid arthritis? J Neuroimmunol 2005; 158:106-11.

25. Forrest CM, Mackay GM, Stoy N, Stone TW, Darlington LG. Inflammatory status and kynurenine metabolism in rheumatoid arthritis treated with melatonin. Br J Clin Pharmacol 2007;64:517-26.

26. Cutolo M, Maestroni GJ, Otsa K, Aakre 0, Villaggio B, Capellino S, et al. Circadian melatonin and cortisol levels in rheumatoid arthritis patients in winter time: a north and south Europe comparison. Ann Rheum Dis 2005; 64:212-6.

27. Maestroni G, Otsa K, Cutolo M. Melatonin treatment does not improve rheumatoid arthritis. $\mathrm{Br} \mathrm{J}$ Clin Pharmacol 2008 2008;65:797-8.

28. Schlaghecke R, Beuscher D, Kornely E, Specker C. Effects of glucocorticoids in rheumatoid arthritis. Diminished glucocorticoid receptors do not result in glucocorticoid resistance. Arthritis Rheum 1994 Aug:37:1127-31.

29. Buttgereit F, da Silva JA, Boers M, Burmester GR, Cutolo M, Jacobs J, et al. Standardised nomenclature for glucocorticoid dosages and glucocorticoid treatment regimens: current questions and tentative answers in rheumatology. Ann Rheum Dis 2002;61:718-22.

30. Kirwan J, Power L. Glucocorticoids: action and new therapeutic insights in rheumatoid arthritis. Curr Opin Rheumatol 2007;19:233-7.

31. Hoes JN, Jacobs JW, Boers M, Boumpas D, Buttgereit F, Caeyers N, et al. EULAR evidence based recommendations on the management of systemic glucocorticoid therapy in rheumatic diseases. Ann Rheum Dis 2007:66:1560-7.

32. Bijlsma JW, Jacobs J. Innovative use of glucocorticoids in patients with rheumatoid arthritis. Lancet 2008;371:183-4.

33. Arnett FC, Arnett FC, Edworthy SM, Bloch DA McShane DJ, Fries JF, et al. The American Rheumatism Association 1987 revised criteria for the classification of rheumatoid arthritis. Arthritis Rheum 1988;31:315-24.

34. Ranganath VK, Khanna D, Paulus HE. ACR remission criteria and response criteria. Clin Exp Rheumatol 2006;24(6 Suppl 43):S21.

35. Emery P, Breedveld FC, Dougados M, Kalden JR, Schiff MH, Smolen JS. Early referral recommendation for newly diagnosed rheumatoid arthritis: evidence based development of a clinical guide. Ann Rheum Dis 2002;61:290-7. 
36. Yazici Y, Pincus $T$, Kautiainen $H$, Sokka T. Morning stiffness in patients with early rheumatoid arthritis is associated more strongly with functional disability than with joint swelling and erythrocyte sedimentation rate. J Rheumatol 2004;31:1723-6.
37. Soubrier M, Zerkak D, Gossec L, Ayral X, Roux C, Dougados M. Which variables best predict change in rheumatoid arthritis therapy in daily clinical practice? J Rheumatol 2006;33:1243-6.
38. Fries JF, Spitz PW, Mitchell DM, Roth SH, Wolfe F, Bloch DA. Impact of specific therapy upon rheumatoid arthritis. Arthritis Rheum 1986;29:620-7.

39. Fries JF. Reevaluating the therapeutic approach to rheumatoid arthritis: the "sawtooth" strategy. J Rheumatol 1990;17(Suppl 22):12-5.

\section{Access the latest content chosen by our Editors}

BMJ Journals editors select an article from each issue to be made free online immediately on publication. Other material is free after 12 months to non-subscribers. Access the Editor's Choice from the home page - or expand your horizons and see what the other BMJ Journals editors have chosen by following the links on any BMJ Journal home page. 